\title{
Assessment of resource and self-regulation of behavior of students with different sense- forming strategies during the session in remote format behavior
}

\author{
Elena Azarko ${ }^{* 1,2}$, Irina Abakumova ${ }^{1}$, and Igor Kupriyanov ${ }^{1,2}$ \\ ${ }^{1}$ Don State Technical University, 344003, 1, Gagarin sq., Rostov-on-Don, Russia \\ ${ }^{2}$ South Federal University, 344006, 105, Bolshaya Sadovaya str., Rostov-on-Don, Russia
}

\begin{abstract}
The study of the meaning-forming strategies of students studying the specialty "Psychology". The features of resource capacity, styles of self-regulation of behavior, emotional tone and mental activation of students with various semantic strategies during the session in a remote format were studied. In conclusion, conclusions and recommendations are presented with suggestions for using the results in the training of future psychologists.
\end{abstract}

\section{Problem statement}

New time and new millennium have set the rapid pace of constant changes in society, science, scientific thought. The psyche of a modern person is under constant pressure of new reality events, emergencies, the demands of the information society, and personal impressions. The art of "living" in a transitive space and coping with any emerging situations attract the interest of specialists from various professional groups. The research problem has developed at the junction of the demands of the new type of society for a person and a specialist who flexibly responds to the changes taking place around.

Currently, there is an increase in research on the study of the semantic sphere of personality, associated with the understanding of human resources, personal potential and psychological well-being $[1-7,11,13,14,15,16,19,20]$. The sense changes the personality, creates an internal resource, transforms the spiritual principle of a person seeking his own path into matter and action.

The use of innovative methods of sense formation in teaching students ensures the formation of a new type of attitudes, motivation, awareness of values, senses and contributes to the consolidation of general cultural and professional competencies.

Actualization of the semantic sphere of students in teaching the profession of psychologist is associated with the formation of competencies (PC-3, PC-13, PC-14) and research skills of self-organization, self-education and self-regulation, experience of reflexivity. It also promotes the study of their own characteristics through understanding the

*Corresponding author: azarkoem@yandex.ru 
personal senses of learning "I study myself-I understand myself- I accept myself"; to socialized senses through awareness of their professional position "I am a future consultant helping people".

\section{The goal of the research}

To determine the characteristics of resource capacity, styles of self-regulation, mental activation, emotional tone of psychology students with various sense-forming strategies.

\section{Methods}

The following methods were used 1) to study the aspects of sense-making - "Test of lifesense orientations" (LSS) by D.A. Leontyev, 2) to study the current psychoemotional state "Assessment of mental activation, emotional tone" by T.A. Nemchina, 3) "Style of selfregulation of behavior (SSPM)" by V.I. Morosanova, 4) to assess the resource index - "Loss and Acquisition Questionnaire (LAC)" by N.E. Vodopyanova-M. Stein. At the stage of statistical analysis - Student's t-test, Cohen's d, correlation analysis (Pearson's r) were used.

\section{Analysis of publications}

The theoretical provisions, which are the basis of the research, are presented by the directions of the theory of sense and sense-forming strategies (Leontyev D.A., IvanovaT.Yu ; Abakumova I.V., Belova E.V., Godunov M.V., Gurtskoy D.A.); concepts of personal resources (Ivanova T.Yu., Leontiev D.A., Osin E.N., Rasskazova E.I., Kosheleva N.V.; Ilyushina M.I., Krasnoshchechenko I.P.; Kapieva K.R.; Vodopyanova_N.E., Shestakova K.N., Stein M .; Klementyeva M.V .; Hunecke M., Hobfoll S., Sun Young Sung; Doan E. Winkel, Rebecca L. Wyland), studies of self-regulation (Konopkin, Morosanova V.I., Stepansky), psychological well-being (Alexandrova L.A., Lebedeva A.A., Bobozhey V.V.) $[1,2,4,5,6,7-14]$.

According to D.A. Leontyev, the components of semantic structures include personal values, motives, semantic constructs, dispositions, attitudes, personal senses, and empirically registered patterns of behavior. Semantic formations form stable patterns of organization - personal dynamic semantic systems, manifested in the direction of the subject's activity and revealing their internal position [10].

Sense-forming strategies determine the direction and qualitative content of the generated sense-image (Abakumova I.V., Godunov M.V.). A sense-making strategy is a way of forming and developing a system of personal meanings for their content and quality filling, organized under the influence of motives, needs, goals, experience, and subjective relationships, as well as reflecting the specifics and dynamics of an individual's actualization of senses in specific situations of life. The following strategies of sensemaking are considered 1) focused on the goal, process, result; 2) dual - adaptive and developing; 3) hypoadaptive, hyperadaptive, and preadaptive [1, 2, 3].

The resource concept (Hobfoll S.) connects a person's adaptive capabilities with the availability of personal resources that are significant for a person and help him adapt to difficult life situations. Resources are subdivided into: 1) material and non-material (desires, goals); 2) external (social support, family, friends, work, social status) and internal intrapersonal variables (self-esteem, professional skills, optimism, self-control, life values, belief system, etc.); 3) mental and physical conditions; 4) volitional, emotional, energetic characteristics, which are necessary for survival or maintaining health [12]. 
Personal resources are understood as individual psychological characteristics associated with more successful implementation of various types of activities and a higher level of psychological well-being. Attitudes, traits, values, attributive schemes, strategies of behavior and coping with stress, such constructs as "self-efficiency", "resilience", "tolerance to uncertainty", "locus of control", "optimism". "Basic beliefs", "sense of connectedness", "resilience", "skill", "hope", "personal virtues" are presented as personal resources. $[4,5,6,7]$.

Leontiev D.A. divides personal resources into 4 groups 1) psychological resources of stability (value-semantic resources, stable positive self-esteem, internal right to be active and decision-making, and others); 2) psychological resources of self-regulation; 3) motivational resources (subjective vitality, internal motivational orientation as a stable personal disposition, dispositional characteristics of the "flow personality"); 4) instrumental resources (individual characteristics that allow to easily and successfully perform different categories of tasks; instrumental skills and competencies, stereotyped response tactics) [5].

V.I. Morosanova presented the styles of self-regulation: "... the stylistic features of selfregulation are typical for a person and the most significant individual characteristics of selforganization and management of external and internal purposeful activity, which is consistently manifested in its various forms ...". The style of self-regulation is manifested in the way in which a person plans and programs the achievement of life goals, takes into account significant external and internal conditions, evaluates the results and adjusts his activity to achieve subjectively acceptable results, in the extent to which the processes of self-organization are developed and conscious $[5,8]$.

\section{Key results and discussion.}

The study was conducted remotely during the summer examination session (online testing, anonymized Google form); 56 volunteer students of the 1st year, studying in the specialty "Psychology", took part in it.

Table 1. Features of resource capacity and general indicators of meaningfulness of students' life $(\mathrm{M} \pm \sigma)$

\begin{tabular}{|c|c|c|c|c|c|c|c|c|c|c|c|c|}
\hline \multirow[b]{2}{*}{$\begin{array}{r}\text { LSS } \\
\text { level }\end{array}$} & \multicolumn{12}{|c|}{ Results } \\
\hline & $\begin{array}{c}\text { Groups } \\
\text { (number of }\end{array}$ & & $\begin{array}{c}\text { General } \\
\text { LSS }\end{array}$ & 1 & 2 & 3 & 4 & 5 & & rree index & $\begin{array}{c}\text { Cohen' } \\
\text { s d }\end{array}$ & $95 \% \mathrm{CI}$ \\
\hline \multirow{6}{*}{ 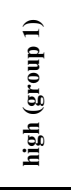 } & \multirow{2}{*}{ total, 24} & $\overline{\mathrm{M}}$ & 122.4 & 38.6 & 36.6 & 30.3 & 25.7 & 37.3 & 2.7 & \multirow{2}{*}{$\begin{array}{c}\mathrm{t}_{\mathrm{emp} 1,3}= \\
1.025\end{array}$} & \multirow[t]{2}{*}{0.63} & \multirow{2}{*}{$\begin{array}{l}{[-0.59,} \\
1.83]\end{array}$} \\
\hline & & $\sigma$ & 5.3 & 2.8 & 3.0 & 2.4 & 1.9 & 2.5 & 1.4 & & & \\
\hline & \multirow{2}{*}{ male, 1} & $\overline{\mathrm{M}}$ & 120 & 37 & 38 & 29 & 25 & 36 & 2.1 & & & \\
\hline & & $\sigma$ & 0 & 0 & 0 & 0 & 0 & 0 & 0 & & & \\
\hline & \multirow{2}{*}{ female, 23} & $\overline{\mathrm{M}}$ & 122.5 & 38.7 & 36.5 & 30.4 & 25.7 & 37.3 & 2.8 & \multirow{2}{*}{$\begin{array}{l}t_{\text {emp 1,2 }}= \\
2.822 *\end{array}$} & \multirow[t]{2}{*}{0.83} & \multirow{2}{*}{$\begin{array}{l}{[0.22,} \\
1.43] \\
\end{array}$} \\
\hline & & $\sigma$ & 5.4 & 2.9 & 3.1 & 2.4 & 2.0 & 2.5 & 1.4 & & & \\
\hline \multirow{6}{*}{ 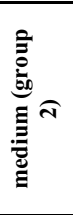 } & \multirow[b]{2}{*}{ total, 28} & $\overline{\mathrm{M}}$ & 98.7 & 30.3 & 28.5 & 25.2 & 20.6 & 30.9 & 1.8 & \multirow{2}{*}{$\begin{array}{c}\mathrm{t}_{\text {emp } 1,2}= \\
3.187 \\
*\end{array}$} & \multirow[t]{2}{*}{0.92} & \multirow{2}{*}{$\begin{array}{l}{[0.34,} \\
1.49]\end{array}$} \\
\hline & & $\sigma$ & 9.0 & 3.5 & 5.0 & 4.3 & 2.3 & 3.3 & 0.9 & & & \\
\hline & \multirow{2}{*}{ male, 5} & $\overline{\mathrm{M}}$ & 103.6 & 35.2 & 28 & 28.8 & 22.6 & 31.6 & 1.36 & & & \\
\hline & & $\sigma$ & 6.7 & 4.3 & 1.9 & 3.0 & 3.2 & 3.4 & 0.3 & & & \\
\hline & \multirow{2}{*}{ female, 23} & $\overline{\mathrm{M}}$ & 98.7 & 30.3 & 28.5 & 25.2 & 20.6 & 30.9 & 1.8 & \multirow{2}{*}{$\begin{array}{l}t_{\text {emp } 1,2}= \\
2.822^{*}\end{array}$} & \multirow[t]{2}{*}{0.83} & \multirow{2}{*}{$\begin{array}{l}{[0.22,} \\
1.43]\end{array}$} \\
\hline & & $\sigma$ & 9.0 & 3.5 & 5.0 & 4.3 & 2.3 & 3.3 & 0.9 & & & \\
\hline \multirow{6}{*}{ 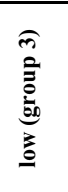 } & \multirow{2}{*}{ total, 3} & $\overline{\mathrm{M}}$ & 67.7 & 17.3 & 19.0 & 17.3 & 12.7 & 20.3 & 1.9 & \multirow{2}{*}{$\begin{array}{c}t_{\text {emp } 1,3}= \\
1.025\end{array}$} & \multirow[t]{2}{*}{0.63} & \multirow{2}{*}{$\begin{array}{l}{[-0.59,} \\
1.83]\end{array}$} \\
\hline & & $\sigma$ & 15.9 & 5.1 & 6.2 & 3.1 & 2.5 & 6.4 & 1.5 & & & \\
\hline & \multirow{2}{*}{ male, 2} & $\overline{\mathrm{M}}$ & 73 & 19.5 & 21.5 & 19 & 12.5 & 19 & 2.2 & & & \\
\hline & & $\sigma$ & 18.4 & 4.9 & 6.4 & 1.4 & 3.5 & 8.5 & 2.0 & & & \\
\hline & \multirow{2}{*}{ female, 1} & $\overline{\mathrm{M}}$ & 57 & 13 & 14 & 14 & 13 & 23 & 1.2 & & & \\
\hline & & $\sigma$ & 0 & 0 & 0 & 0 & 0 & 0 & 0 & & & \\
\hline & \multirow[t]{2}{*}{ TOTAL, 55} & $\overline{\bar{M}}$ & 107.8 & 33.7 & 31.5 & 27.3 & 22.6 & 33.1 & 2.2 & & & \\
\hline & & $\sigma$ & 16.7 & 6.4 & 6.4 & 4.8 & 4.0 & 5.3 & 1.2 & & & \\
\hline
\end{tabular}


Note: Scales of the LSS test - 1 - Purpose in life; 2 - Process of life; 3 - Life results; 4 Locus of control-Self; 5 - Locus of control-Life;marked * $-\mathrm{p}<0.05$.

The results of 1 person were discarded. The analysis of the results of 55 people ( 8 male, 47 female) was carried out; the results are summarized below in tables 1-3.

The following were taken into account 1) The LSS test - the scales "purpose in life"; "life process"; "life results"; "locus of control - self"; "locus of control - life" and general scale of sensefulness of life; 2) resource index; 3) in assessing mental activation and emotional tone - mental activation, interest, emotional tone, tension, comfort; 4) when identifying the style of self-regulation - the general level of self-regulation, planning, modeling, programming, evaluating the results, flexibility, independence.

Commenting on table 1 , it can be stated that group 1 with high rates of LSS $(122.4 \pm$ 5.3) comprised 24 people; group 2 with average rates of LSS $(98.7 \pm 9.0)$ - 28 people; with low rates of LSS $(67.7 \pm 15.9)-3$ people. The majority $(87 \%)$ of future psychologist-firstyear students are characterized by the sensefulness of their lives, an understanding of goals that give a time perspective and direction to daily actions; the perception of the process of life as colourful, interesting, filled with events and senses; possession of sufficient freedom of choice and the ability to control their lives. Resource values vary from 0.1 to $7 ; 5$ people have a low level - less than about 0.8; high (more than 1.2) and average values (0.9-1.2) have $91 \%$ of the study participants.

The hypothesis was the assumption that people with different levels of LSS will have different levels of resource index - for people with high values of the general indicator of sensefulness of life, high indicators of resource will be characteristic.

The assumption was partially confirmed. Higher values of resource index are found in people with high levels of LSS. When comparing groups with high and low LSS values, higher values of the resource index (RI) are observed in group 1 with high LSS values (RI $=2.7 \pm 1.4)$ compared with group $3(\mathrm{RI}=1.9 \pm 1,5)$, Cohen's $\mathrm{d}=0.63$ (mean effect size), $95 \%$ CI $[-0.59,1.83]$. The differences are statistically insignificant $\left(\mathrm{t}_{\text {emp }} 1,3=1.025\right.$ does not reach critical values at $\mathrm{p}=0.05 \mathrm{t}(0.05)=2.060$ for groups 1,3 at $\mathrm{N}=27$ and degrees of freedom $\mathrm{DF}=25$ ). Resource capacity significantly differs in groups with high and medium values of the overall level of LSS (Cohen's $d=0.92$ (large effect size), 95\% CI [0.34, 1.49], $\mathrm{t}_{\text {emp }} 1.2=3.187$ at $\mathrm{p}=0.01 \mathrm{t}(0.01)=2.678$ for groups 1.2 at $\mathrm{N}=52$ and $\left.\mathrm{DF}=50\right)$; as well as in females from these groups (Cohen's $d=0.83$ (large effect size), 95\% CI [0.22, 1.43], $\mathrm{t}_{\text {emp }} 1.2=2.822$ at $\mathrm{p}=0.01 \mathrm{t}(0.01)=2.692$ for groups 1.2 at $\mathrm{N}=46$ and degrees of freedom $\mathrm{DF}=44)$.

The groups with preferential strategies are identified - 1) the sense-forming strategy "Purpose", 2) the sense-forming strategy "Process"; 3) the semantic strategy "Results" (see table 2). It was supposed to reveal significant differences in the emotional tone, resource capacity and self-regulation of students with different sense-forming strategies.

Table 2. Features of emotional tone, resource capacity and self-regulation of students with different sense-forming strategies

\begin{tabular}{|c|c|c|c|c|c|}
\hline & \multicolumn{5}{|c|}{ results (groups, number of persons) } \\
\hline & values & & total & male & female \\
\hline \multicolumn{3}{|c|}{ sense-forming strategy "Goal" } & total, 24 & male, 4 & female, 20 \\
\hline \multirow{5}{*}{$\begin{array}{l}\text { Assessment of } \\
\text { mental } \\
\text { activation, } \\
\text { emotional tone }\end{array}$} & Mentalactivation & $\overline{\mathrm{M}} \pm \sigma$ & $10.1 \pm 4.8$ & $12.25 \pm 5.9$ & $9.7 \pm 4.6$ \\
\hline & Interest & $\overline{\mathrm{M}} \pm \sigma$ & $7.7 \pm 2.9$ & $10.5 \pm 2.4$ & $7.2 \pm 2.7$ \\
\hline & Emotionaltone & $\overline{\mathrm{M}} \pm \sigma$ & $6.8 \pm 2.7$ & $8 \pm 3.3$ & $6.5 \pm 2.5$ \\
\hline & Stress & $\overline{\mathrm{M}} \pm \sigma$ & $11.2 \pm 4.0$ & $11.75 \pm 5.4$ & $11.1 \pm 3.8$ \\
\hline & Comfort & $\overline{\mathrm{M}} \pm \sigma$ & $8.1 \pm 3.3$ & $8.25 \pm 3.5$ & $8.1 \pm 3.3$ \\
\hline \multicolumn{2}{|r|}{ Resourceindex } & $\overline{\mathrm{M}} \pm \sigma$ & $2.5 \pm 1.4$ & $1.65 \pm 0.4$ & $2.7 \pm 1.5$ \\
\hline Self-regulationstyle & $\begin{array}{l}\text { General level of self- } \\
\text { regulation }\end{array}$ & $\overline{\mathrm{M}} \pm \sigma$ & $33.1 \pm 5.2$ & $32 \pm 5.2$ & $33.1 \pm 4.9$ \\
\hline
\end{tabular}




\begin{tabular}{|c|c|c|c|c|c|}
\hline & Planning & $\overline{\mathrm{M}} \pm \sigma$ & $6.2 \pm 1.7$ & $6.25 \pm 1.5$ & $6.1 \pm 1.7$ \\
\hline & Modeling & $\overline{\mathrm{M}} \pm \sigma$ & $6.5 \pm 1.7$ & $6 \pm 2.8$ & $6.4 \pm 1.8$ \\
\hline & Programming & $\overline{\mathrm{M}} \pm \sigma$ & $6.9 \pm 1.5$ & $6 \pm 1.4$ & $7.0 \pm 1.6$ \\
\hline & Resultsevaluation & $\overline{\mathrm{M}} \pm \sigma$ & $6.5 \pm 1.4$ & $6.75 \pm 1.0$ & $6.6 \pm 1.4$ \\
\hline & Flexibility & $\overline{\mathrm{M}} \pm \sigma$ & $6.9 \pm 1.7$ & $5.75 \pm 2.1$ & $6.9 \pm 1.6$ \\
\hline & Independence & $\overline{\mathrm{M}} \pm \sigma$ & $5.7 \pm 2.0$ & $6.25 \pm 2.1$ & $5.8 \pm 2.0$ \\
\hline & \multicolumn{2}{|c|}{ sense-forming strategy "Process" } & total, 21 & male, 1 & female, 20 \\
\hline \multirow{5}{*}{$\begin{array}{l}\text { Assessment of } \\
\text { mental } \\
\text { activation, } \\
\text { emotional tone }\end{array}$} & Mentalactivation & $\overline{\mathrm{M}} \pm \sigma$ & $9.2 \pm 4.7$ & $9 \pm 0$ & $9.3 \pm 4.8$ \\
\hline & Interest & $\overline{\mathrm{M}} \pm \sigma$ & $7.2 \pm 2.4$ & $13 \pm 0$ & $7.0 \pm 2.1$ \\
\hline & Emotionaltone & $\overline{\mathrm{M}} \pm \sigma$ & $6.6 \pm 3.0$ & $4 \pm 0$ & $6.7 \pm 3.0$ \\
\hline & Stress & $\overline{\mathrm{M}} \pm \sigma$ & $9.8 \pm 3.7$ & $6 \pm 0$ & $10.0 \pm 3.7$ \\
\hline & Comfort & $\overline{\mathrm{M}} \pm \sigma$ & $7.4 \pm 2.7$ & $4 \pm 0$ & $7.6 \pm 2.7$ \\
\hline & Resourceindex & $\overline{\mathrm{M}} \pm \sigma$ & $2.7 \pm 1.5$ & $2.1 \pm 0$ & $2.7 \pm 1.5$ \\
\hline \multirow{7}{*}{ Self-regulationstyle } & $\begin{array}{l}\text { General level of self- } \\
\text { regulation }\end{array}$ & $\overline{\mathrm{M}} \pm \sigma$ & $33.1 \pm 4.3$ & $33 \pm 0$ & $33.1 \pm 4.4$ \\
\hline & Planning & $\overline{\mathrm{M}} \pm \sigma$ & $6.6 \pm 1.9$ & $7 \pm 0$ & $6.6 \pm 1.9$ \\
\hline & Modeling & $\overline{\mathrm{M}} \pm \sigma$ & $6.5 \pm 1.5$ & $8 \pm 0$ & $6.4 \pm 1.5$ \\
\hline & Programming & $\overline{\mathrm{M}} \pm \sigma$ & $7.0 \pm 1.6$ & $4 \pm 0$ & $7.2 \pm 1.5$ \\
\hline & Resultsevaluation & $\overline{\mathrm{M}} \pm \sigma$ & $6.6 \pm 1.4$ & $6 \pm 0$ & $6.6 \pm 1.4$ \\
\hline & Flexibility & $\overline{\mathrm{M}} \pm \sigma$ & $7.0 \pm 1.7$ & $8 \pm 0$ & $6.9 \pm 1.7$ \\
\hline & Independence & $\overline{\mathrm{M}} \pm \sigma$ & $5.4 \pm 1.7$ & $6 \pm 0$ & $5.4 \pm 1.8$ \\
\hline \multicolumn{3}{|c|}{ sense-forming strategy "Results" } & total, 28 & male, 3 & female, 25 \\
\hline \multirow{5}{*}{$\begin{array}{c}\text { Assessment of } \\
\text { mental } \\
\text { activation, } \\
\text { emotional tone }\end{array}$} & Mentalactivation & $\overline{\mathrm{M}} \pm \sigma$ & $9.3 \pm 4.9$ & $13.33 \pm 6.7$ & $8.8 \pm 4.5$ \\
\hline & Interest & $\overline{\mathrm{M}} \pm \sigma$ & $7.3 \pm 2.5$ & $9.67 \pm 2.1$ & $7.0 \pm 2.4$ \\
\hline & Emotionaltone & $\overline{\mathrm{M}} \pm \sigma$ & $6.7 \pm 2.8$ & $9.33 \pm 2.3$ & $6.4 \pm 2.8$ \\
\hline & Stress & $\overline{\mathrm{M}} \pm \sigma$ & $11.0 \pm 3.9$ & $13.67 \pm 4.7$ & $10.6 \pm 3.8$ \\
\hline & Comfort & $\overline{\mathrm{M}} \pm \sigma$ & $8.0 \pm 3.3$ & $9.67 \pm 2.5$ & $7.8 \pm 3.3$ \\
\hline & Resourceindex & $\overline{\mathrm{M}} \pm \sigma$ & $2.4 \pm 1.4$ & $1.5 \pm 0.3$ & $2.5 \pm 1.5$ \\
\hline \multirow{7}{*}{ Self-regulationstyle } & $\begin{array}{l}\text { General level of self- } \\
\text { regulation }\end{array}$ & $\overline{\mathrm{M}} \pm \sigma$ & $33.0 \pm 4.2$ & $31.67 \pm 6.4$ & $33.2 \pm 4.0$ \\
\hline & Planning & $\overline{\mathrm{M}} \pm \sigma$ & $6.1 \pm 1.6$ & $6.00 \pm 1.7$ & $6.1 \pm 1.6$ \\
\hline & Modeling & $\overline{\mathrm{M}} \pm \sigma$ & $6.0 \pm 1.8$ & $5.33 \pm 3.1$ & $6.0 \pm 1.7$ \\
\hline & Programming & $\overline{\mathrm{M}} \pm \sigma$ & $7.1 \pm 1.2$ & $6.67 \pm 0.6$ & $7.2 \pm 1.3$ \\
\hline & Results evaluation & $\overline{\mathrm{M}} \pm \sigma$ & $6.6 \pm 1.2$ & $7.00 \pm 1.0$ & $6.5 \pm 1.2$ \\
\hline & Flexibility & $\overline{\mathrm{M}} \pm \sigma$ & $7.1 \pm 1.6$ & $5.00 \pm 1.7$ & $7.3 \pm 1.4$ \\
\hline & Independence & $\overline{\mathrm{M}} \pm \sigma$ & $5.8 \pm 1.7$ & $6.33 \pm 1.5$ & $5.7 \pm 1.7$ \\
\hline
\end{tabular}

According to the methodology for assessing mental activation by T.A. Nemchina, the higher the scores (more than 8), the worse is the psycho-emotional state of the subject. Critical conditions are when scores are more than 15 points.

Commenting on the obtained values, it can be seen that in the studied subgroups there is no low level of self-regulation and low values for individual styles. There are high values of the general level of self-regulation from 33 points with a different combination of styles.

It is possible to form the following characteristics of the studied subgroups in terms of mental activation, emotional tone, resource capacity and self-regulation styles of students with various semantic strategies.

Feature 1 - sense-forming strategy "Purpose":

- when assessing mental activation the following is revealed: - mental activation and stress approaching a critical state of 15 points $(10.1 \pm 4.8$ and $11.2 \pm 4.0$, respectively); average level of comfort $(8.1 \pm 3.3)$; low values indicating well-being - emotional tone $(6.8 \pm 2.7)$, interest $(7.7 \pm 2.9)$; in young men, mental activation approaching a critical value $(12.25 \pm$ 5.9);

- the general level of self-regulation is high $(33.1 \pm 5.2)$; predominant styles of selfregulation with an average and high level (6-7 points and more) - 1st place - programming 
and flexibility; 2nd place - modeling and evaluation of results; 3rd place - planning;the resource index is high $(2.5 \pm 1.4)$, higher than the other two subgroups, and the females of this subgroup have high values $(2.7 \pm 1.5)$.

Feature 2 - sense-forming strategy "Process":

- when assessing mental activation, the following is revealed: the average level - mental activation $(9.2 \pm 4.7)$; voltage $(9.8 \pm 3.7)$; low values indicating the well-being of the psychoemotional sphere - emotional tone $(6.6 \pm 3.0)$; interest $(7.2 \pm 2.4)$; comfort $(7.4 \pm$ 2.7);

- the general level of self-regulation is high $(33.1 \pm 4.3)$; predominant styles of selfregulation are expressed by the average and high level (6-7 points or more) - 1 st place programming and flexibility; 2nd place - planning and evaluation of results; 3rd place modeling;high resource index $(2.7 \pm 1.5)$; the females of this subgroup also have the highest values $(2.7 \pm 1.5)$.

Feature 3 - sense-forming strategy "Result":

- when assessing mental activation, low values were revealed, indicating the well-being of the psychoemotional sphere - emotional tone $(6.7 \pm 2.8)$, interest $(7.3 \pm 2.5)$; average values of comfort $(8.0 \pm 3.3)$; approaching a critical state - stress $(11.0 \pm 3.9)$ and mental activation $(9.3 \pm 4.9)$; these values are especially expressed among the young men of this group (13.67 \pm 4.7 and $13.33 \pm 6.7$, respectively);

- the general level of self-regulation is high $(33.0 \pm 4.2)$; predominant styles of selfregulation with an average and high level (6-7 points or more) - 1st place, programming and flexibility - higher values in the compared subgroups; 2nd place - evaluation of results; 3rd place - planning; in this subgroup, the highest values of the style of independence $(5.8 \pm$ $1.7)$; high resource index $(2.4 \pm 1.4)$; lower values of resource capacity among males of this subgroup $(1.5 \pm 0.3)$. The differences in the studied subgroups are insignificant.

Table 3. The relationship between resource index, mental activation, styles of selfregulation and scales of the LSS test

\begin{tabular}{|c|c|c|c|c|c|c|}
\hline \multirow[t]{2}{*}{ Scales } & \multicolumn{6}{|c|}{ Pearson's r // LSS scales } \\
\hline & 1 & 2 & 3 & 4 & 5 & General LSS \\
\hline Mental activation & $-0.23 *$ & $-0.42 * *$ & $-0.39 * * *$ & $-0.39 * * *$ & $-0.32 * *$ & $-0.39 * * *$ \\
\hline Interest & $-0.49 * * * *$ & $-0.46^{* * * *}$ & $-0.49 * * * *$ & $-0.45 * * * *$ & $-0.39 * * * *$ & $-0.53 * * * *$ \\
\hline Emotional tone & $-0.49 * * * *$ & $-0.58 * * * *$ & $-0.60 * * * *$ & $-0.51 * * * *$ & $-0.45^{* * * *}$ & $-0.62 * * * *$ \\
\hline Stress & -0.01 & -0.11 & -0.05 & -0.14 & -0.12 & -0.14 \\
\hline Comfort & $-0.49 * * * *$ & $-0.62 * * * *$ & $-0.64 * * * *$ & $-0.52 * * * *$ & $-0.53 * * * *$ & $-0.63 * * * *$ \\
\hline Resource index & $0.32 * *$ & $0.38 * * *$ & $0.30 * *$ & $0.29 * *$ & $0.39 * * *$ & $0.40 * * *$ \\
\hline $\begin{array}{l}\text { General level of self- } \\
\text { regulation }\end{array}$ & $0.23 *$ & $0.38 * * *$ & $0.27 * *$ & $0.28 * *$ & $0.36^{* * *}$ & $0.34 * * *$ \\
\hline Planning & -0.15 & 0.03 & -0.10 & -0.04 & -0.08 & -0.07 \\
\hline Modeling & $0.45 * * *$ & $0.39 * * *$ & $0.46^{* * *}$ & $0.39 * * *$ & $0.45 * * *$ & $0.48 * * *$ \\
\hline Programming & 0.21 & $0.31 * *$ & $0.30 * *$ & $0.30 * *$ & $0.31 * *$ & $0.31 * *$ \\
\hline Resultsevaluation & 0.21 & $0.27 * *$ & $0.27 * *$ & 0.17 & $0.28 * *$ & $0.24 *$ \\
\hline Flexibility & 0.20 & $0.26^{*}$ & 0.08 & 0.14 & $0.24 *$ & $0.24 *$ \\
\hline Independence & -0.13 & -0.06 & -0.15 & -0.10 & -0.14 & -0.12 \\
\hline
\end{tabular}

Note: Scales of the LSS test - 1 - Purpose in life; 2 - Process of life; 3 - Life results; 4 Locus of control-Self; 5 - Locus of control-Life;

- marked correlations: ${ }^{*}$ - weak at $\mathrm{p}=0.1 \mathrm{r} 0.1=0.228$; ** - moderate at $\mathrm{p}=0.05 \mathrm{r} 0.05=$ $0.271 ; * * *$ - strong at $\mathrm{p}=0.01 \mathrm{r} 0.01=0.351 ; * * * *$ - at $\mathrm{p}=0.001 \mathrm{r} 0.001=0.439$ for $\mathrm{N}=55$ and $\mathrm{DF}=52$. 
Discussing the results obtained, it can be assumed that in the situation of forced distance learning during the summer session, the system of personal senses and related actual psychoemotional states affects the activity of the zone of singularity of sense and undergoes a change, subjectively perceived as tension and mental activation. Continuing the discussion, according to studies, as a result of depletion of resources, especially in connection with the efforts made to volitional control over the situation, the ability to psychological well-being and self-regulation is significantly reduced $[5,16,17,19]$.

Table 3 below shows the results of the correlation analysis. It was assumed that the determinants of sense-making strategies are associated with resourcefulness, selfregulation, and mental activation.

It was revealed that more powerful connections are observed when comparing the general indicator of the meaningfulness of life with RI, individual styles of self-regulation.

\section{Conclusions and perspectives.}

The following conclusions can be drawn

1. High and average values of LSS are typical for $87 \%$ of future psychologist-first grade students. During the session in the distance format, $91 \%$ have a high and medium level of resource index. The assumption that high values of the general level of the sensefulness of life determine high values of resource index was partially confirmed (Cohen's $d=0.92$, $95 \%$ CI $[0.34 ; 1.49]$ for groups 1 and 2 ).

2. Individuals with different sense-forming strategies are characterized by:

- common features are high resource index values; general level of self-regulation, 1st place was taken by predominant styles of self-regulation, programming and flexibility; selfregulation style - independence - reduced; in the current psycho-emotional state, mental activation and stress are enhanced;

-distinguishing features - 1) of the sense-forming strategy "Purpose": a combination of different styles of self-regulation (modeling, evaluation of results, planning); high values of resource capacity among goal-oriented girls; critical values of mental activation in goaloriented young men; optimal interest and emotional tone; 2) of the sense-forming strategy "Process": the absence of critical values in the assessment of current psycho-emotional states in combination with a favorable emotional tone, comfort, interest and high values of resource index, especially among females who are process-oriented; combination of styles of self-regulation (planning, evaluation of results and modeling); 3) of the sense-forming strategy "Results": a combination of styles of self-regulation (assessment of results, planning) with higher values of styles, flexibility and independence; critical values of mental activation and stress in young men who are result-oriented; optimal interest and emotional tone. The differences in the studied subgroups are insignificant.

3. A prospect in the educational process in the preparation of future psychologists can be: 1) the use of diagnostic techniques of online testing, which allows students to gain experience of self-study, understanding the current situation of personal development and planning the zone of proximal development and, further, prospects as a future psychologist; 2) the inclusion in the practice of teaching academic disciplines of techniques that contribute to the development of reflexivity, skills in the use of various styles of selfregulation and self-control; 3) the use in disciplines of a practical orientation of techniques for the formation of experience of resource states as professionally important qualities.

4. From the scientific point of view, the topic of the interconnection of resources, psychological well-being, self-regulation of persons with various semantic strategies is promising. 


\section{Recommendations}

1. The inclusion in the educational process of elements of such research on the study of the individual-typological characteristics of psychology students makes it possible to actualize their ideas about themselves as a subject of future professional activity, awareness and training of their professional competencies (PC-3, PC-13, PC-14) ...

2.From the point of view of practical psychology, the experience of such work gives students, starting from the 1st year, the understanding of the logic of providing psychological assistance: from diagnostics to analysis with conclusions about growth zones and, further, to the formation of recommendations and the selection of tasks and tactics of psychological counseling. The use of information and communication technologies at the diagnostic stage demonstrates the capabilities of the digital environment to minimize the time for diagnosis and processing of the subject's results.

\section{References}

1. I. Lachnit, C. L. Park, L. S. George, Processing and Resolving Major Life Stressors: An Examination of Meaning-Making Strategies. Cognitive Therapy and Research, 44(5), 1015-1024 (2020) DOI: 10.1007/s10608-020-10110-7

2. E. A. Yu, E. C. Chang, Relational meaning in life as a predictor of interpersonal wellbeing: A prospective analysis. Personality and Individual Differences, 168, 110377 (2021) DOI: 10.1016/j.paid.2020.110377

3. I. V. Abakumova, M. V. Godunov, D. A. Gurtskoy, Self-transcendence as the basis of the pre-adaptive strategy of sense formation. Scientific and pedagogical review, 3, 185190 (2020) DOI:10.23951 / 2307-6127-2020-3-185-190

4. B. Glavan, O. Negru-Subtirica, O. Benga, The Struggle to Find Meaning: A Mixed Methodology Study on Meaning-Making and Identity. Emerging Adulthood, 8(5), 367372 (2020) DOI: 10.1177/2167696819841760

5. D. Leontiev, Meaning at the crossroads of evolution, culture, and person Evolutionary. Studies in Imaginative Culture, 4(1), 31-33 (2020) DOI: 10.26613/esic.4.1.162

6. I. F. Young, D. Sullivan, J. Hart, R. Palitsky, Insecurity orientations: A person-centered approach to existential concerns. Personality and Individual Differences, 168, 110288 (2021) DOI: 10.1016/j.paid.2020.110288

7. M. I. Ilyushina, I. P. Krasnoschechenko, Conceptualization of ideas about resource subjectivity, Applied legal psychology, 1(38), 138-146 (2017)

8. K. R. Kapieva, Psychic resource of personality: patterns and determinants of development. Humanization of education, 3, 75-81 (2015)

9. L. Finkelstein-Fox, J. M. Pavlacic, E. M. Buchanan, S. E. Schulenberg, C. L. Park, Valued Living in Daily Experience: Relations with Mindfulness, Meaning, Psychological Flexibility, and Stressors. Cognitive Therapy and Research, 44(2), 300310 (2020) DOI: 10.1007/s10608-019-10062-7

10. D. A. Leontiev, Personal meaning: A challenge for psychology, The Journal of Positive Psychology, 8:6, 459-470 (2013) DOI: 10.1080/17439760.2013.830767

11. M. Hunecke, Psychological resources for sustainable lifestyles. Bonn, 68 (2012) http://www.denkwerkzukunft.de/downloads/reportpsychologicalresources.PDF (Last accessed 21.05.2020) 
12. S. E. Hobfoll, N. R. Stevens, A. K. Zalta, Expanding the Science of Resilience: Conserving Resources in the Aid of Adaptation Psychological Inquiry, 26(2), 174-180 (2015) DOI: 10.1080/1047840X.2015.1002377

13. Sun Young Sung, Yung Won Rhee, Jae Lee, Jin Nam Choi, Dual pathways of emotional competence towards incremental and radical creativity: resource caravans through feedback-seeking frequency and breadth. Psychology European Journal of Work and Organizational Psychology, 29(3), 421-433 (2020) https://doi.org/10.1080/1359432X.2020.1718654

14. D. E. Winkel, R. L. Wyland, A new perspective on psychological resources: Unanticipated consequences of impulsivity and emotional intelligence. Journal of Occupational and Organizational Psychology, 84(1), 78-94 (2011) https://onlinelibrary.wiley.com/doi/abs/10.1348/2044-8325.002001 (Last accessed 11.05.2020)

15. P. Russo-Netzer, A. Shoshani, Authentic inner compass, well-being, and prioritization of positivity and meaning among adolescents. Personality and Individual Differences. 167, 110248 (2020) doi.org/10.1016/j.paid.2020.110248

16. A. Patricia, College Students' Use and Acceptance of Emergency On-line Learning Due to COVID-19. International Journal of Educational Research Open (2020) doi:https://doi.org/10.1016/j.ijedro.2020.100011

17. P. D. MacIntyre, T. Gregersen, S. Mercer, Language teachers' coping strategies during the Covid-19 conversion to online teaching: Correlations with stress, wellbeing and negative emotions. System, 94, $102352 \quad$ (2020) https://doi.org/10.1016/j.system.2020.102352

18. J. Ki, Learning and Teaching Online During Covid-19: Experiences of Student Teachers in an Early Childhood Education Practicum. International Journal of Early Childhood, 52, 145-158 (2020) source: https://ink.springer.com/article/10.1007/s13158-020-00272-6 (Last accessed 11.06.2020)

19. A. M. Alenezi, The relationship of students' emotional intelligence and the level of their readiness for online education: A contextual study on the example of university training in Saudi Arabia, Obrazovanie i Nauka, 22(4), 89-109 (2020) DOI: 10.17853/1994-5639-2020-4-89-109

20. C. Wang, H. Zhao, The Impact of COVID-19 on Anxiety in Chinese University Students. Frontiers in Psychology, 11, 1168 (2020) DOI: 10.3389/fpsyg.2020.01168 